\title{
Relevance of limited-transpiration trait for lentil (Lens culinaris Medik.) in South Asia
}

\author{
Julie Guiguitant $^{\mathrm{a}, \mathrm{b}}$, Hélène Marrou ${ }^{\mathrm{c}}$, Vincent Vadez ${ }^{\mathrm{d}}$, Priyanka Gupta ${ }^{\mathrm{a}}$, Shiv Kumar ${ }^{\mathrm{a}}$, \\ Afshin Soltani ${ }^{\mathrm{e}}$, Thomas R. Sinclair ${ }^{\mathrm{f}}$, Michel Edmond Ghanem ${ }^{\mathrm{a}, *}$ \\ a Crop Physiology Laboratory, International Center for Agricultural Research in the Dry Areas (ICARDA), Crop Physiology Laboratory, North-Africa Platform, Rabat, \\ Morocco \\ ${ }^{\mathrm{b}}$ Montpellier SupAgro, Montpellier, France \\ c UMR System, Montpellier SupAgro, Montpellier, France \\ d International Crops Research Institute for the Semi-Arid Tropics (ICRISAT), System Analysis for Climate Smart Agriculture, Patancheru, Greater Hyderabad, Telangana, \\ India \\ e Agronomy Group, Gorgan University of Agricultural Sciences and Natural Resources Gorgan, Iran \\ ${ }^{\mathrm{f}}$ Department of Crop Science, North Carolina State University (NCSU), Raleigh, NC, United States
}

\section{A R T I C L E I N F O}

\section{Keywords:}

Lentil

Limited transpiration trait

Vapor pressure deficit

South Asia

SSM

Crop model

\begin{abstract}
A B S T R A C T
Drought is one of the most important environmental factors that limit crop production. It has been hypothesized that a limited-transpiration trait under high vapor pressure deficit (VPD) is a mechanism for water conservation leading to yield increase under water-deficit conditions. The first research objective was to compare expression of limited-transpiration $\left(\mathrm{TR}_{\mathrm{lim}}\right)$ in lentil (Lens culinaris Medik.) observed by whole-plant measurements in controlled environments and under natural conditions outdoors during a high VPD period. Seventeen lentil genotypes were studied. All genotypes showed a linear increase with increasing VPD under natural conditions. Differences were observed among genotypes in their expression of $\mathrm{TR}_{\mathrm{lim}}$ with increasing VPD in the controlled environment. Almost all genotypes showed a VPD breakpoint at approximately $3.4 \mathrm{kPa}$. A simulation analysis was conducted across South Asia to identify where, how often, and how much this trait in lentil would benefit farmers with four different VPD breakpoint scenarios (VPD breakpoint at 3.4, 2.2, $1.1 \mathrm{kPa}$, and VPD-insensitive). Results showed that the limited-transpiration trait at a low simulated threshold (1.1 kPa) can result in improved lentil performance in drought-prone environments and that the impact of the trait on lentil productivity varies with geography and environment. The largest average yield increase was simulated for drought-prone environments $\left(250 \mathrm{~g} \mathrm{~m}^{-2}\right)$. Outcomes from this simulation study provide insights into the plausible role of the limited-transpiration trait under high VPD in future lentil genetic improvement and implies that a search for germplasm with a breakpoint as low as $1.1 \mathrm{kPa}$ needs to be made.
\end{abstract}

\section{Introduction}

Lentil (Lens culinaris Medik.) is an annual food legume that plays an important role in the food and nutritional security of millions (Kumar et al., 2012), especially in South Asia which is one of the largest production areas in the developing world (Chen et al., 2011). About a quarter of the worldwide production of lentils is from India (second largest producing country in the world), most of which is consumed in the domestic market (Janzen et al., 2014). Around 90\% of the production in India comes from the Northeastern and central part of the country. The southern and western parts of the country hardly contribute to India's total lentil production.
In subtropical regions of Pakistan, India, Nepal and Bangladesh, lentil is grown as a winter crop primarily on residual soil moisture from monsoon rains under rain-fed condition (Materne and Siddique, 2009). Hence, the present yield of lentil in India is reported to be low (Kumar et al., 2012) due to terminal drought and high temperatures, particularly during flowering and seed growth (Mishra et al., 2016). Climate change is expected to increase temperatures and an increase in extremes of rainfall as well as an increased risk of drought mostly in subtropical region (Donat et al., 2016). Therefore, the development of drought-tolerant cultivars is one of the major objectives of national and international lentil breeding programs.

One of the strategies advanced to enhance crop yields for late-

\footnotetext{
* Corresponding author.

E-mail address: m.ghanem@cgiar.org (M.E. Ghanem).
} 
season, water-deficit conditions is early-season soil-water conservation so that more water is available to complete seed filling under drought conditions, which occur more commonly late in the growing season (Sinclair et al., 2005). Richards and Passioura (1989) approached this possibility by selecting wheat genotypes with smaller diameter xylem elements in the stem. While they found a yield increase with smallxylem germplasm under drought conditions, this approach was never pursued beyond the experimental stage.

A specific trait that is especially promising for allowing conservative soil water use is one in which transpiration rate is limited under high, midday vapor pressure deficit (VPD). The partial restriction of transpiration rate under high VPD limits the rate of soil water use, and raises the transpiration efficiency, allowing the crop to conserve water to support plant growth later in the season when drought develops (Devi et al., 2015; Sinclair et al., 2016). However, the partial decrease in stomatal conductance would also constrain photosynthetic rate (Vadez et al., 2014). Yet, the punctual loss in mass production due to stomata closure may be offset by water savings in the soil for use later in the growing season. If there is a late-season water deficit, genotypes with a breakpoint (BP) in their response to increasing VPD have the possibility of using the conserved soil water to sustain physiological activity during seed fill and generate a greater yield than genotypes that are VPD insensitive (Sinclair et al., 2016). Lowering BP of lentil might be an especially good way to improve yield under water-limited conditions. On the other hand, if there is late-season rainfall or if the decrease of photosynthetic rate is too high with partial stomata closure, the benefit of conserved water would not be obtained, thus, a lower breakpoint would lead to equal or lower yield than a line that does not express a breakpoint (Vadez et al., 2014; Sinclair et al., 2016). Hence, the yield response to limited-transpiration trait is likely to vary across growing seasons and locations.

Sinclair et al. (2005) examined the possible benefits for sorghum (Sorghum bicolor L.) from limiting transpiration rate (TR) to a constant, maximum value under high levels of air vapor pressure deficit (VPD) even when soil moisture contents are high. Using a crop model that simulated sorghum growth in Australia, they reported a yield increase in about $75 \%$ of the seasons over 100 years at four different locations.

Considerable evidence has confirmed that the limited-transpiration trait, assessed under well-watered conditions, is expressed in selected genotypes of several crop species, including soybean (Glycine max (L.) Merr.) (Fletcher et al., 2007; Sinclair et al., 2008; Sadok and Sinclair, 2009a,b; Gilbert et al., 2011; Seversike et al., 2013), peanut (Arachis hypogaea L.) (Devi et al., 2010; Shekoofa et al., 2013), sorghum (Sorghum bicolor L.) (Gholipoor et al., 2010; Shekoofa et al., 2014; Kholová et al., 2014; Riar et al., 2015), chickpea (Cicer arietinum L.) (Zaman-Allah et al., 2011), pearl millet (Pennisetum glaucum (L.) (Kholová et al., 2010), cowpea (Vigna unguiculata L.) (Belko et al., 2013), maize (Zea mays L.) (Yang et al., 2012; Gholipoor et al., 2013), and wheat (Triticum aestivum L.) (Rebetzke et al., 2003; Schoppach and Sadok, 2012). With regard to lentil, no information is available to date on diversity among lentil genotypes in the transpiration response to vapor pressure deficit (VPD). Since lentil is grown in South Asia in environments with high VPD conditions in the post rainy season, the limited-transpiration trait might be especially important. In these environments during the lentil cycle, the midday estimates of VPD is often above $1.5 \mathrm{kPa}$ and can reach values above $3 \mathrm{kPa}$.

Not only is there no information among lentil genotypes about the expression of the limited-transpiration trait, there is no indication of the possible yield benefit of developing genotypes that express the trait. To assess the possible benefits of the limited-transpiration trait over a range of environments and geographical area, it is necessary to develop cross-cutting tools, such as crop models, that can be used to judge the relative merits of modifications of a specific trait. Such an assessment needs to consider the interaction of modifications with environmental variables, and importantly, to generate indications of advantage in where and how often an alterations will benefit farmers in specific geographical locations.

The complexity associated with genotype $\times$ environment $\times$ management interactions can be explored in a quantitative assessment using a mechanistic simulation model (Soltani and Sinclair, 2012; Messina et al., 2015). Simulation studies proved useful to evaluate the impact of a limited-transpiration rate at high VPD in sorghum (Sinclair et al., 2005), soybean (Sinclair et al., 2010, 2014) and maize (Messina et al., 2015). Other simulations studies in chickpea - another cool-season legume- have shown that the limited transpiration trait can result in 3-7\% increased grain yield in Iran depending on location and soil depth (Soltani and Sinclair, 2012). A lentil version of the SSM-Legumes (Simple Simulation Model-Legumes) model was developed and proven robust in evaluating variation in phenological development and yield of lentil in a range of environments, with different rainfall patterns, in the Middle East (Ghanem et al., 2015a), and investigating the roles of changing phenology and sowing dates on the possible expansion of lentil culture in East Africa (Ghanem et al., 2015b).

There were two objectives for this study. The first objective was to investigate the possible genotypic variation in lentil for TR response to VPD. Specifically, the question was whether there are lentil genotypes that exhibit a breakpoint in their response to increasing VPD above which there is little or no further increase in transpiration rate. Seventeen genotypes were selected as initial candidates based on results from previous field screening (Table 1). Transpiration rate of these selected lines was measured, in a first experiment, under natural daily VPD variation. In a second experiment, TR was measured under controlled environments (growth chambers) for plants subjected to a wide range of VPD (2.5 $\mathrm{kPa}$ up to around $6.5 \mathrm{kPa}$ ). The second objective of this study was to use a simulation model to do a geospatial assessment of the likely effect of genotypic variation in the limitedtranspiration trait on yield performance of lentil at a regional scale in the South Asia. It was demonstrated that the limited-transpiration trait can result in improved lentil yield in drought-prone areas and that the impact of the trait on lentil productivity varies with geography, environment type, and level of expression of the trait.

\section{Material and methods}

\subsection{Genetic material}

Seventeen lentil genotypes belonging to different genetic backgrounds and different reported characteristics were used in this study (Table 1). These lines were described in the literature as being drought sensitive, drought tolerant, heat sensitive or heat tolerant (Table 1).

\subsection{Transpiration response to $V P D$}

Two independent experiments were carried out to document TR response to VPD; (i) the first experiment was outdoors to test the TR response to the natural daily variation of VPD, (ii) the second was conducted under controlled conditions (growth chamber) to maximize the range of VPD to which the plants were exposed.

Each experiment included the seventeen genotypes of lentil. For both experiments, seeds were sown in plastic pots (diameter $22 \mathrm{~cm}$ and height $20 \mathrm{~cm}$ ) filled with $5 \mathrm{~kg}$ of alfisol mixed with sand and manure (5:3:1). The soil was fertilized with di-ammonium phosphate at the rate of $0.3 \mathrm{~g} \mathrm{~kg}^{-1}$ soil. A small hole was drilled in the center of the end cap of the pot for drainage. Three seeds inoculated with a Rhizobium strain were sown in each pot. Plants were grown in a greenhouse in Hyderabad (India) under the following conditions: day/night temperature $30 / 25{ }^{\circ} \mathrm{C}$, and relative humidity ranging between $50 \%$ and $80 \%$ during the day. Ten days after sowing, each pot was thinned to a single plant. Pots were watered every other day. Plants were grown for 4 weeks before measurements started in each of the two experiments.

The day before the measurements, pots were watered to full capacity until water flowed from the bottom of the pots, then the pots 


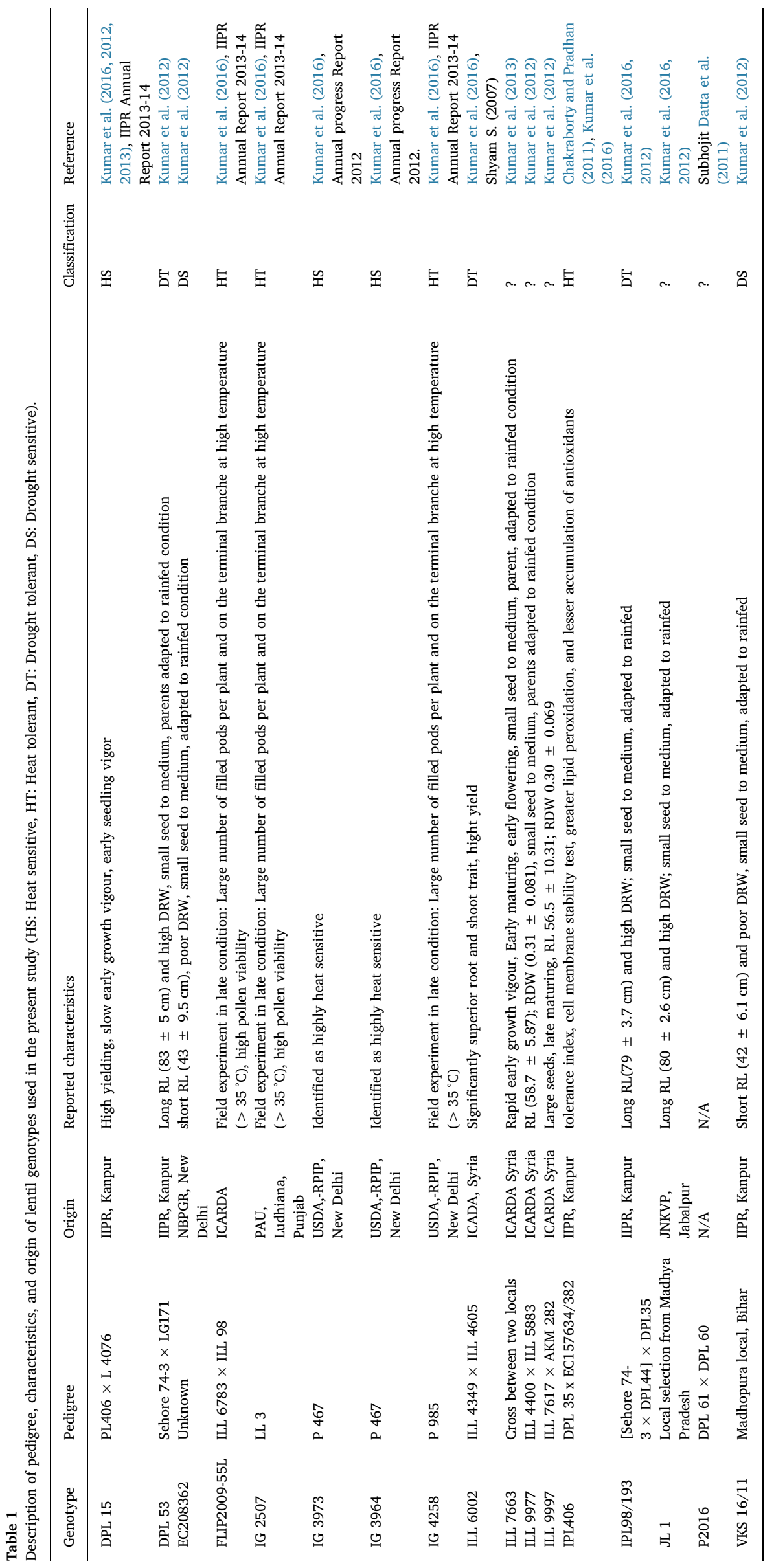


Table 2

Soil classification and parameters for South Asia, as needed by the SSM model. (WISE database).

\begin{tabular}{|c|c|c|c|c|c|c|}
\hline \multirow[t]{4}{*}{ Parameter } & \multicolumn{6}{|l|}{ Soil type } \\
\hline & Soil & Soil & Soil & Soil Type 4 & & \\
\hline & Type 1 & Type 2 & Type 3 & & Type 5 & Type 6 \\
\hline & & & Value & & & \\
\hline Mains soils & $\begin{array}{l}\text { Acrisols, Cambisols, Gleysols, Leptosols, } \\
\text { Solochacks }\end{array}$ & Arenosols & $\begin{array}{l}\text { Calcisol, Fluvisols, } \\
\text { Nitisols }\end{array}$ & Lixisols & Luvisols & Vertisols \\
\hline Depth (mm) & 980 & 981 & 934 & 971 & 1000 & 982 \\
\hline Number of layers & 5 & 5 & 5 & 5 & 5 & 5 \\
\hline Soil albedo & 0.13 & 0.15 & 0.13 & 0.14 & 0.14 & 0.09 \\
\hline Curve number (run-off) & 84 & 68 & 68.6 & 77 & 68 & 85 \\
\hline Drainage factor & 0.4 & 0.48 & 0.43 & 0.32 & 0.36 & 0.48 \\
\hline Soil water content at saturation $\left(\mathrm{m}^{3} \mathrm{~m}^{-3}\right)$ & 0.42 & 0.40 & 0.41 & 0.39 & 0.35 & 0.39 \\
\hline Soil water content at Drained upper limit $\left(\mathrm{m}^{3} \mathrm{~m}^{-3}\right)$ & 0.24 & 0.23 & 0.24 & 0.27 & 0.28 & 0.27 \\
\hline Extractable water $\left(\mathrm{m}^{3} \mathrm{~m}^{-3}\right)$ & 0.13 & 0.13 & 0.13 & 0.13 & 0.13 & 0.13 \\
\hline $\begin{array}{l}\text { Soil moisture availability index at sowing }(1=\text { DUL, } \\
\quad 0=\mathrm{LL})\end{array}$ & 1 & 1 & 1 & 1 & 1 & 1 \\
\hline Soil coarse fraction & 17.5 & 14.5 & 13.6 & 15.8 & 15.6 & 13.7 \\
\hline Bulk density & 1.39 & 1.46 & 1.42 & 1.49 & 1.57 & 1.46 \\
\hline
\end{tabular}

DUL: drained upper limit, LL: lower limit

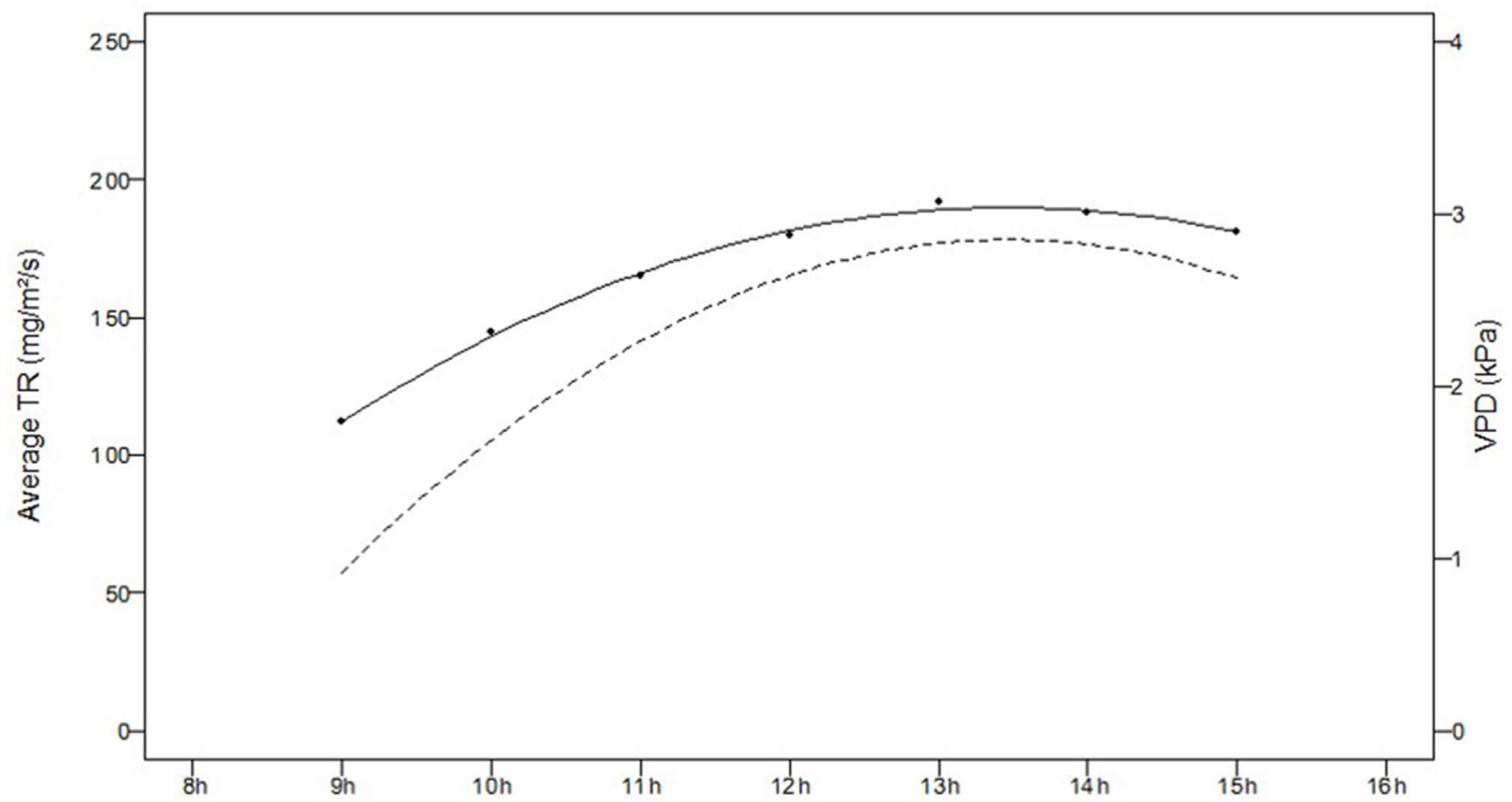

Time

Fig. 1. Evolution of transpiration rate (TR in $\mathrm{mg} \mathrm{m}^{-2} \mathrm{~s}^{-1}$ ) and the VPD during the daily cycle of measurement. (Solid line: Average transpiration, dotted line: VPD).

were allowed to drain through the night. Before measurements, pots were sealed in plastic bags to eliminate soil evaporation. At the end of the experiments the leaf area was measured and TR expressed as water loss per unit of leaf area and time $\left(\mathrm{g} \mathrm{H}_{2} \mathrm{O} \mathrm{cm}{ }^{-2} \mathrm{~h}^{-1}\right)$.

For the outdoor experiment, genotypes were replicated six times in a randomized design. TR was assessed for the well-watered plants under natural, outdoor variation of VPD during the course of a clear day. All pots were transferred from the greenhouse to outdoors at 6:00 AM (India Standard Time) and were set on benches for 1 day of acclimation before starting the experiment. All pots were watered to full capacity until water flowed from the bottom of the pots, then the pots were allowed to drain through the night. The following day, pots were bagged with plastic bags to keep soil evaporation to minimum and weighed ( $0.1 \mathrm{~g}$ precision) every hour starting in the morning from 8:00
AM (India Standard Time) when VPD was low until 16:00 PM (India Standard Time), when the VPD decreased following the midday maximum. Hourly transpiration rates (TR) were calculated as the weight difference between successive measurements. A thermo-hygrograph sensor (Tinytag Ultra 2 TGU-4500 Gemini Datalogger Ltd, Chichester, UK) was positioned at the crop canopy height. Atmospheric VPD was calculated from the recorded temperature and relative humidity (RH). Average of temperatures and RHs recorded at $5 \mathrm{~min}$ interval were used for calculating each $60 \mathrm{~min}$ VPD. The hourly VPD values ranged between $0.91 \mathrm{kPa}$ and $2.63 \mathrm{kPa}$.

For the controlled-environment experiment, four pots of each of the 17 genotypes were saturated with water, allowed to drain overnight, bagged and transferred to three growth chambers for 1 day of acclimation. The pots were placed in a random design in the central area on a 


\section{DPL 53}

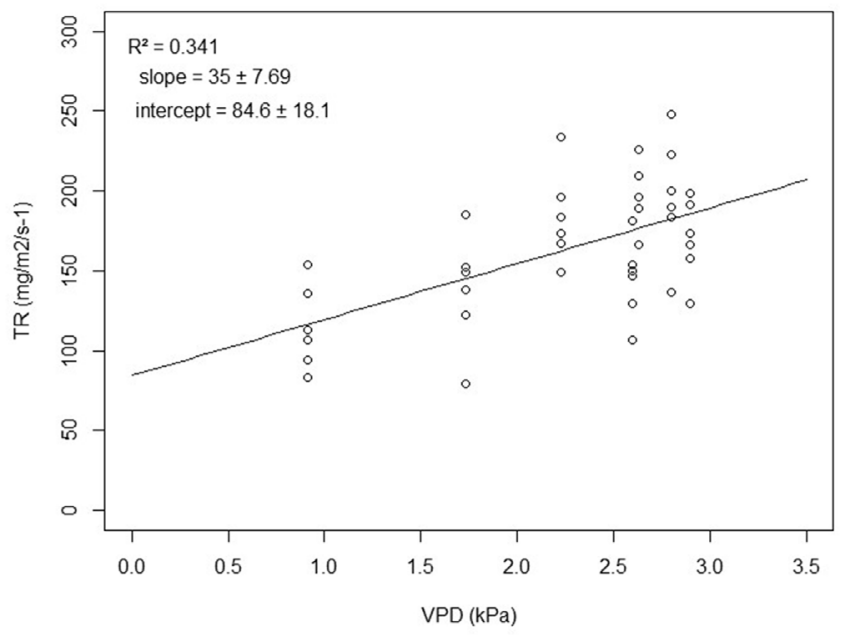

Fig. 2. Example of transpiration rate (TR in $\mathrm{mg} \mathrm{m}^{-2} \mathrm{~s}^{-1}$ ) response to natural outside vapor pressure deficit (VPD in $\mathrm{kPa}$ ). Results are from genotype DPL53.

\section{ILL 9997}

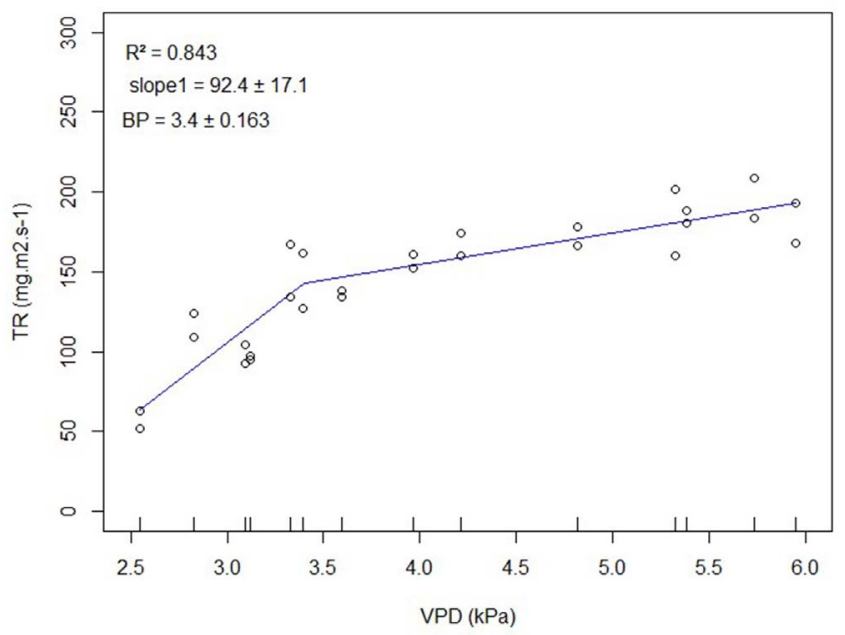

Fig. 3. Example of segmented regression of transpiration rate (TR in $\mathrm{mg} \mathrm{m}^{-2} \mathrm{~s}^{-1}$ ) response for various vapor pressure deficit (VPD in $\mathrm{kPa}$ ) in growth chambers. Results are from genotype ILL997.

steel grid platform installed at mid-height in a walk-in growth chambers ( $2.5 \mathrm{~m} \times 1.9 \mathrm{~m} \times 1.3 \mathrm{~m}$, Conviron). The temperature of the growth chamber was $32{ }^{\circ} \mathrm{C}$ and the photosynthetic photon flux density (PPFD) was $\sim 550 \mathrm{mmol} \mathrm{m}^{-2} \mathrm{~s}^{-1}$ at the plant canopy level during a $13 \mathrm{~h} \mathrm{light}$ period. The day following acclimation, the transpiration response to VPD was assessed for each plant. A temperature and humidity sensor (Tinytag Ultra 2 TGU-4500 Gemini Datalogger Ltd, Chichester, UK) was mounted at canopy height inside a punched thermocool box of each chamber to measure the air temperature and $\mathrm{RH}$ at 5-min intervals. Average of temperature and RH over 60-min was used to calculate VPD.

Changes in TR of the well-watered plants caused by a ladder of increasing VPD regimes was achieved by increasing temperature (total temperature increase of $8-10{ }^{\circ} \mathrm{C}$ ) and decreasing $\mathrm{RH}$ (to $25 \%$ ) starting from $2.54 \mathrm{kPa}$ up to $6.49 \mathrm{KPa}$ (with an exposure of $45 \mathrm{~min}$ at each VPD) were recorded. The time required to weigh all the pots (around $10 \mathrm{~min}$ ) was used to increase the VPD to the next level on the ladder. Transpiration of each genotype was estimated from the loss in pot weight after the $60 \mathrm{~min}$ exposure to a given VPD. Plants were allowed to adapt to the change in VPD for one hour before they were weighted to measure plant transpiration. In total eight VPD levels were done.

\subsection{Statistical analysis}

Data were first filtered to remove possible outliers resulting from weighing error by using the Interquartile Range Rule (IQR) (Tukey, 1977). The homogeneity of the results of the three growth chambers and the leaf area within the different genotypes were tested with variances analysis (ANOVA/ANCOVA) performed using the R statistical software (http://www.R-project.org/).

A two-segment linear regression (model 1) (Eq. (1)) was fit to the transpiration data against VPD for each genotype using the "Segmented" R package (Muggeo, 2008).

$\left\{\begin{array}{cc}T R_{i}=\beta_{0}+\beta_{1} V P D_{i} & \text { ifVPD } \\ T R_{i}=\beta_{2} V P D_{i}+\beta_{0}+\left(\beta_{1}-\beta_{2}\right) B P & \text { ifVPD }\end{array}\right.$

According to such parameterization, $\beta_{0}$ is the intercept of the first segment, $\beta_{1}$ is the slope of the first segment, $\beta_{2}$ is the slope of the second segment, and BP is the VPD breakpoint. The Segmented R package employs the Davies (1987) test for testing whether there is a significant difference in slope before and after the breakpoint. The alpha value for this test was considered at 0.05 and the null hypothesis is (Eq. (2)):

$H_{0}:\left(\beta_{1}-\beta_{2}\right)(B P)=0$

For each genotype, the data were tested with the Davies test first, to see whether or not the breakpoint existed, then, depending on the result, the data were fitted with the two-segmented regression or with a linear regression. For those genotypes found to be represented by the two segments, the regression analysis generated the VPD breakpoint between the two linear segments.

To determine whether the regression differed significantly among genotypes, the two-linear segment model was fitted to data considering an effect of the genotype on parameters $b_{0}, b_{1}, b_{2}$, and BP (model 2). The model with genotype effect (model 2) was compared to the initial model (model 1) via an F-test (Eq. (3)) (Nickerson et al., 1989):

$\mathrm{F}=\frac{\left(\mathrm{SSE}_{\text {model1 }}-\mathrm{SSE}_{\text {model } 2}\right) /(4 \times(\mathrm{g}-1))}{\mathrm{SSE}_{\text {model } 2} /(\mathrm{N}-4 \times \mathrm{g})}$

The SSE (sum of squared errors of prediction) of the model 2 $\left(\mathrm{SSE}_{\text {model2 }}\right)$ is the sum of the individual SSEs of all the segmented regression for each genotype and the SSE of the model 1 (SSE $\left.\mathrm{Smodel}_{1}\right) 1$ is the SSE of the segmented regression obtained with all the data combined. $N$ is the total number of observation and $g$ is the number of genotypes. Confidences intervals at $95 \%$ were used to compare the estimated parameters (intercept $\left(b_{0}\right)$, slope $1\left(b_{1}\right)$, slope $2\left(b_{2}\right)$, and VPD breakpoint (BP) among genotypes. When the intervals of two different estimated parameters were overlapping, it was considered that there were no significant differences between genotypes for a given parameter.

\subsection{Simulations}

\subsubsection{Model description}

To predict the potential yield of lentil in South Asia, the SSMlegume (Simple Simulation Model) model was used (Soltani and Sinclair, 2012). SSM is a non-calibrated, mechanistic, comparatively simple model that can be used to assess the relative merits of various management practices and of plant trait changes in specific geographical locations. The SSM model has been parameterized for lentil and demonstrated to result in robust predictive capacity in evaluating variation in phenological development and yield of lentil in a range of environments, with different rainfall patterns in the Middle East (Ghanem et al., 2015a) and East Africa (Ghanem et al., 2015b). To simulate a transpiration response to VPD variation, it was necessary to modify a part of the original model to allow calculations at hourly time steps to account for changes in VPD over the day.

Daily minimum and maximum temperatures were used to calculate 
Table 3

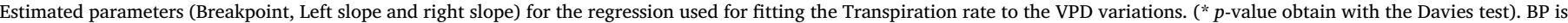
the breakpoint, $\mathrm{CI}$ is the confidence interval.

\begin{tabular}{|c|c|c|c|c|c|c|c|c|c|}
\hline \multirow[t]{2}{*}{ Genotype } & \multirow[t]{2}{*}{ Class. } & \multicolumn{2}{|c|}{ Break point } & \multicolumn{2}{|c|}{ Left slope } & \multicolumn{2}{|c|}{ Right slope } & \multirow[t]{2}{*}{ R-squared } & \multirow[t]{2}{*}{ P-value* } \\
\hline & & BP & CI (95\%) & S1 & CI (95\%) & S2 & CI (95\%) & & \\
\hline IG 2507 & HS & 3.39 & {$[3.01 ; 3.75]$} & 119.6 & {$[60.18 ; 179.0]$} & 22.4 & {$[8.97 ; 35.83]$} & 0.79 & $<0.001$ \\
\hline IG4258 & DT & 3.35 & {$[3.08 ; 3.62]$} & 165.2 & {$[100.7 ; 229.7]$} & 24.07 & {$[9.49 ; 38.65]$} & 0.83 & $<0.0001$ \\
\hline FLIP2009-55L & DS & 3.76 & {$[3.06 ; 4.45]$} & 93.83 & {$[42.41 ; 145.3]$} & 20.72 & {$[-3.58 ; 45.03]$} & 0.75 & 0.02 \\
\hline IG 3973 & HT & 3.31 & {$[2.94 ; 3.67]$} & 170.20 & {$[69.51 ; 270.9]$} & 24.87 & {$[9.14 ; 40.6]$} & 0.77 & $<0.001$ \\
\hline IG 3964 & HT & 3.38 & {$[3.08 ; 3.74]$} & 138.2 & {$[71.36 ; 205.1]$} & 27.01 & {$[11.89 ; 42.12]$} & 0.81 & $<0.001$ \\
\hline IPL98/193 & HS & 3.39 & {$[2.87 ; 3.90]$} & 83.68 & {$[35.57 ; 131.8]$} & 19.09 & {$[4.15 ; 34.03]$} & 0.71 & 0.01 \\
\hline DPL 53 & HS & linear & linear & 35.85 & {$[22.98 ; 48.72]$} & linear & linear & 0.56 & 0.1 \\
\hline JL 1 & HT & 3.40 & {$[3.00 ; 3.80]$} & 109.60 & {$[62.89 ; 156.3]$} & 28.28 & {$[13.78 ; 42.79]$} & 0.84 & 0.001 \\
\hline EC208362 & DT & 3.39 & {$[2.937 ; 3.84]$} & 80.41 & {$[40.95 ; 119.5]$} & 27.59 & {$[18.71 ; 36.47]$} & 0.87 & $<0.01$ \\
\hline VKS $16 / 11$ & $?$ & 3.87 & {$[3.01 ; 4.72]$} & 96.74 & {$[33.69 ; 159.8]$} & 20.13 & {$[-9.67 ; 49.94]$} & 0.70 & 0.03 \\
\hline ILL6002 & $?$ & 3.37 & {$[2.95 ; 3.79]$} & 99.79 & {$[50.27 ; 149.3]$} & 29.64 & {$[18.45 ; 40.83]$} & 0.85 & $<0.01$ \\
\hline ILL7663 & $?$ & 3.38 & {$[2.86 ; 3.91]$} & 134.1 & {$[43.3 ; 224.9]$} & 30.01 & {$[9.48 ; 50.53]$} & 0.71 & 0.02 \\
\hline DPL-15 & HT & 3.33 & {$[2.98 ; 3.68]$} & 110.8 & {$[55.9 ; 165.7]$} & 20.45 & {$[8.03 ; 32.86]$} & 0.78 & $<0.001$ \\
\hline P2016 & DT & 3.33 & {$[2.82 ; 3.84]$} & 113.9 & {$[34.52 ; 193.2]$} & 28.32 & {$[15.93 ; 40.72]$} & 0.80 & $<0.01$ \\
\hline IPL406 & $?$ & 3.33 & {$[2.81 ; 3.85]$} & 129.9 & {$[24.09 ; 235.7]$} & 13.48 & {$[-10.43 ; 37.39]$} & 0.47 & 0.02 \\
\hline ILL 9977 & $?$ & 3.33 & {$[2.95 ; 3.71]$} & 133.90 & {$[61.66 ; 206.1]$} & 24.62 & {$[8.30 ; 40.94]$} & 0.75 & $<0.01$ \\
\hline ILL 9997 & DS & 3.40 & {$[3.06 ; 3.74]$} & 92.39 & {$[57.0 ; 127.8]$} & 19.67 & {$[8.68 ; 30.66]$} & 0.84 & $<0.0001$ \\
\hline
\end{tabular}

\section{DPL 53}

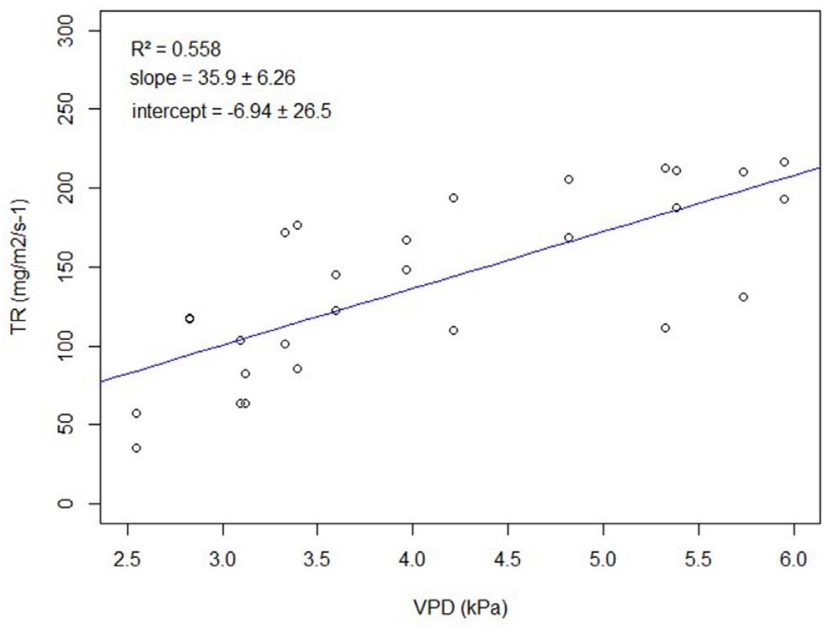

Fig. 4. Example of linear regression of transpiration rate (TR in $\mathrm{mg} \mathrm{m}^{-2} \mathrm{~s}^{-1}$ ) response for various vapor pressure deficit (VPD in $\mathrm{kPa}$ ) in growth chambers. Results are from genotype DPL53 that showed a linearly increasing transpiration rate with increasing VPD (no breakpoint).

hourly temperature, assuming a harmonic change through the day with the maximum temperature assumed to occur at 15:00 (Goudriaan and van Laar, 1994; Sinclair et al., 2005). Hourly incoming radiation was estimated as a fraction of the daily radiation, according to latitude, daylength and hour of the day. The hourly VPD was calculated as the difference between the saturated vapor pressure calculated from the temperature at each time step and the absolute atmospheric vapor pressure assumed to be equivalent to the saturated vapor pressure at daily minimum temperature (Sinclair et al., 2005). The dry matter production was calculated at every hour directly based on hourly incoming radiation, daily fraction of intercepted light and daily radiation use efficiency ( $2.05 \mathrm{~g} \mathrm{MJ}^{-1}$ of photosynthetic radiation when mean daily temperature is optimal). The hourly VPD was used to determine the crop response in terms of transpiration rate and dry matter production at every hour. If the calculated VPD was less than the VPD breakpoint (BP), then hourly transpiration rate (TR) was calculated based on growth and the well-established relationship between growth and transpiration (Tanner and Sinclair, 1983). Transpiration was calculated as follows (Eq. (4); Soltani and Sinclair, 2012) based on hourly dry matter production (DDMP, $\mathrm{g} \mathrm{m}^{-2} \mathrm{~h}^{-1}$ ), hourly vapor pressure deficit (VPD, $\mathrm{kPa}$ ), and a constant transpiration efficiency coefficient (TEC).

$\mathrm{TR}=\frac{(\mathrm{DDMP} \times \mathrm{VPD})}{\mathrm{TEC}}$

If the VPD calculated is greater than the VPD-BP, then the transpiration and carbon accumulation must be adjusted. First, by definition transpiration rates at VPD greater than the VPD-BP were assumed constant at the value calculated for transpiration at VPD-BP. This constancy of TR allows the influence of the VPD-BP to be explored with the simplest response function. Given a partial stomata limitation on gas exchange above VPD-BP, it is also necessary to decrease the original DDMP estimation. The corrective factor used was the ratio in transpiration rates between that calculated based on VPD-BP and that calculated based on actual VPD. Multiplication of the original DDMP estimation by the corrective factor results in a decreased estimate in DDMP for that hourly period. The small temperature increase (usually observed to be less than $1.5^{\circ} \mathrm{C}$ ) due to partial stomata closure were assumed in the model to have a negligible influence on carbon accumulation rate.

\subsubsection{Model entries: weather generation}

To get the variability in simulating the full scope of crop response to weather, it is necessary to simulate crop yield for at least 20 years at each location (Sinclair et al., 2014). To be able to cover the whole South Asia, it was necessary to generate weather data. The National Centers for Environmental Prediction (NCEP) and National Center for Atmospheric Research (NCAR) re-analysis baseline data were used to produce a retroactive record of daily data (Uppala et al., 2005; Dee et al., 2011). The surface grids were analyzed in the Weather Research and Forecasting (WRF) tool to extract daily values for last 30 years at $1^{\circ} \times 1^{\circ}$ point locations in each of the regional blocks. Daily weather data were generated for 447 different locations spanning over India, Afghanistan, Bangladesh, Pakistan and Nepal for 30 years for each location. The quality of the weather data in representing the patterns of rainfall and temperature distribution was verified as in Ghanem et al. (2015b) by comparing generated weather data to available historical weather data for a few locations (data not shown).

\subsubsection{Model parameters: soil and crop parameters}

Soil characteristics were based on the data retrieved from the ISRICWISE international soil profile database (http://www.isric.org/data/ isric-wise-international-soil-profile-dataset). The soil parameters that 

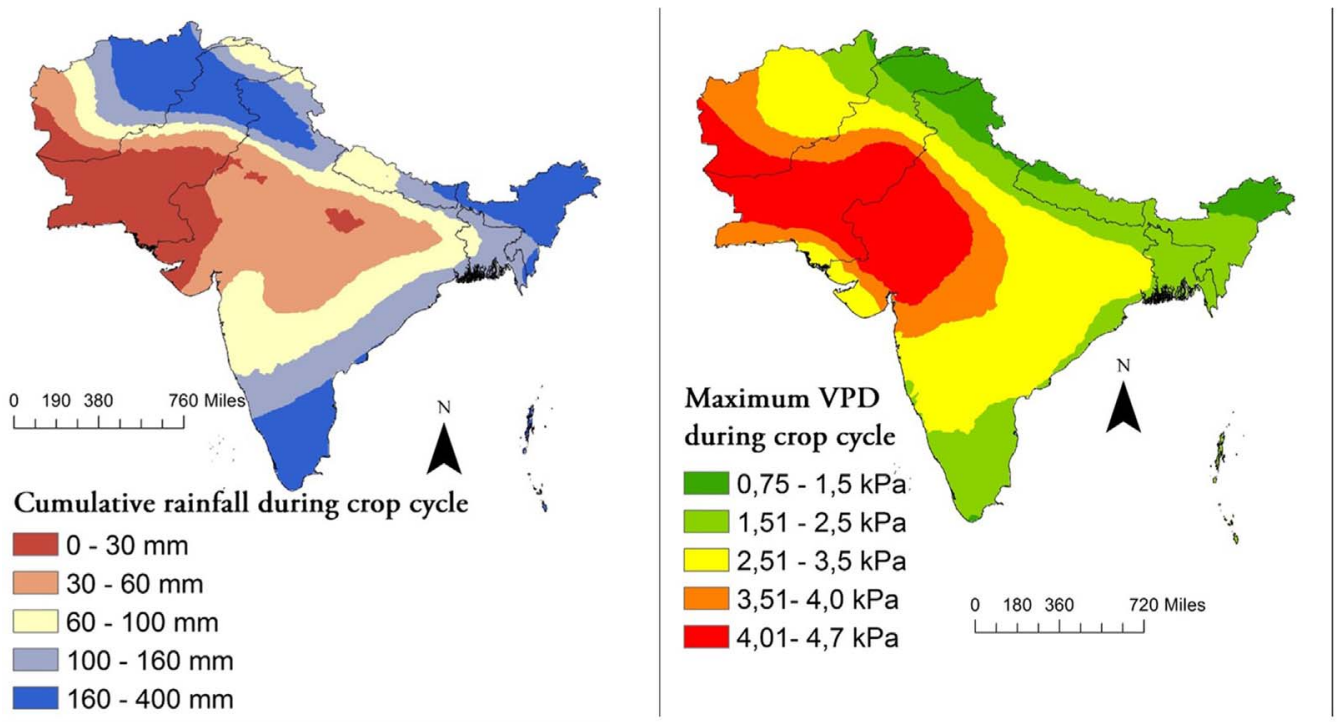

Fig. 5. Cumulative rainfall distribution at simulated locations in South Asia during crop cycle.

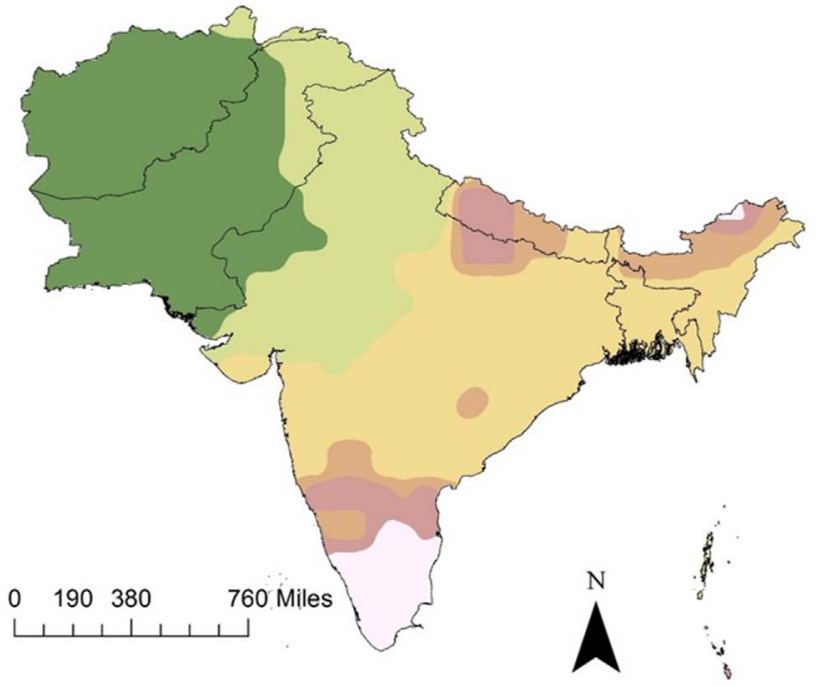

Model sowing date

10 sept -20 sept
$\square \quad 21$ sept -5 oct
$\square 6$ oct -20 oct
$\square$
21 oct -10 nov
$\square 10$ nov -7 dec
$\square 7$ dec -25 dec

Fig. 6. Simulation of model-determined sowing dates for lentil in South Asia.

are required as inputs in the SSM model were compared by performing a principal component analysis to group similar soil types. Soils of South Asia were organized into six categories of soils considered as representative of the soil diversity (Table 2 and Supplementary material figure). The following soils were considered as representative of the different soil categories (each including one or more soil types): Acrisols, Arenosols, Calcisols, Lixisols, Luvisols and Vertisols.

Crop parameters for lentil were the same used in Ghanem et al. (2015a,b). Transpiration efficiency coefficient (TEC) was set to $5 \mathrm{~Pa}$ and potential radiation use efficiency (RUE) was set to $2.05 \mathrm{~g} \mathrm{MJ}^{-1}$ photosynthetic active radiation (Ghanem et al., 2015a). For all simula- tions, crops were grown under rain-fed and non $\mathrm{N}$-limited conditions. The sowing date was not fixed and the model searched in each season for the sowing day. The sowing day was based on the calculation of the relative water content of the soil and corresponded to the last day after a minimum of 10 day, rain-free period, determined as the start date for searching for sowing date. This approach corresponded to the approximate withdrawal dates of the monsoon for each location reported in Fasullo and Webster (2003). Sowing density was fixed at 60 plants $\mathrm{m}^{-2}$. Both sowing date criteria and density corresponded to conventional agronomic practices for lentil.

\subsubsection{Crop yield simulations}

The initial baseline simulations were set for a 'standard' lentil line that expressed limited-transpiration by imposing a VPD breakpoint (BP) at $3.4 \mathrm{kPa}$, above which it was assumed there was no further increase in transpiration rate. This 'standard' value was chosen based on the experimental results reported in this study (Results section below), where the average VPD breakpoint in the growth chamber study of seventeen lentil genotypes was $3.4 \mathrm{kPa}$. Three other scenarios of hypothetical cultivars were tested: a VPD breakpoint set at $2.2 \mathrm{kPa}$, another at $1.1 \mathrm{kPa}$, and a linearly increasing transpiration rate with increasing VPD (VPD-insensitive, no breakpoint).

For each year in each geographical point, the difference between the yield for each of the hypothetical cultivars and the standard lentil simulation with $3.4 \mathrm{kPa}$ BP was calculated. A probability of yield increase was also calculated for each point based on the fraction of years in which the yield increased as a result of the various scenarios of limited-transpiration trait.

\section{Results}

\subsection{TR response to daily VPD variation outdoors}

The transpiration of lentil plants in Experiment 1 was measured under outdoor VPD conditions that varied between $0.9 \mathrm{kPa}$ and $2.9 \mathrm{kPa}$. The daily pattern of TR closely followed the daily pattern of VPD. However, average TR $\left(\mathrm{mg} \mathrm{m}^{-2} \mathrm{~s}^{-1}\right)$ of all lentil genotypes slowed down between 13:00 and 14:00 PM (India standard time) when the VPD reached its maximum values (Fig. 1). Although, the responses of VPD of none of the genotypes was well described by the two-linear segment model. An attempt was made to fit all genotype responses by linear regression (Fig. 2). The linear regression also - did not fit well to the data (R-squared values were between 0.05-0.46; data not shown). 

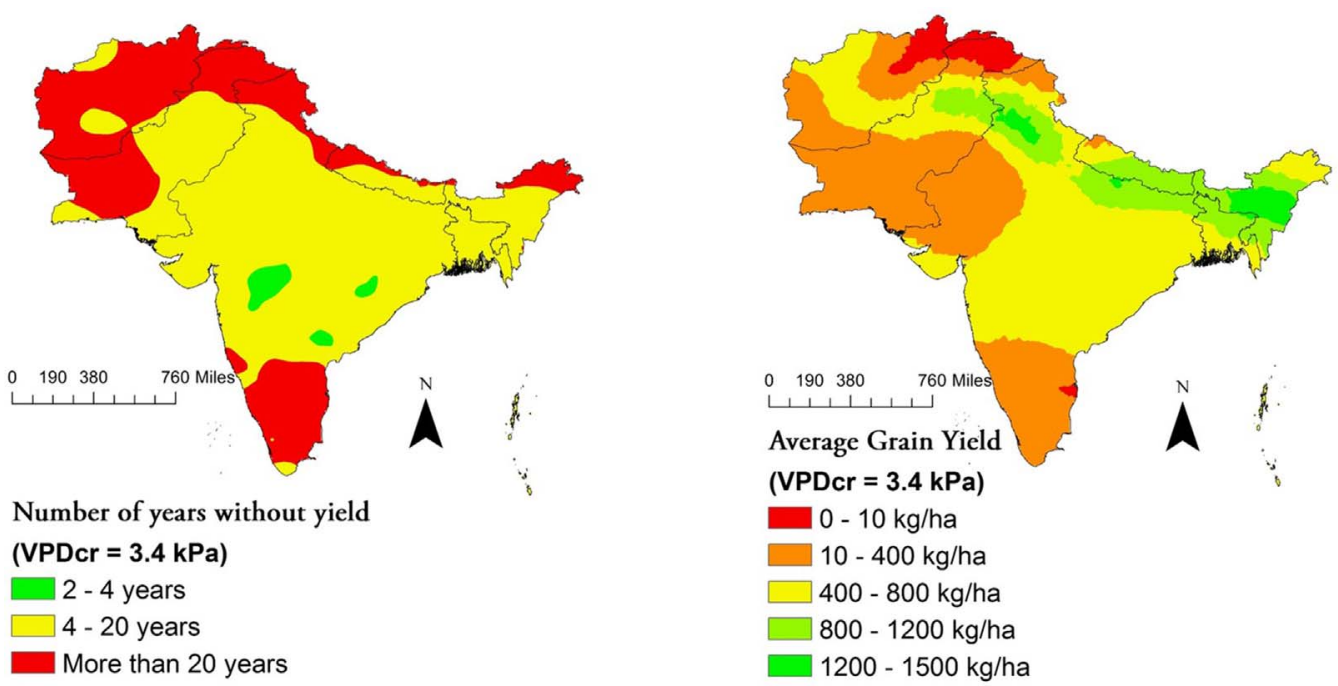

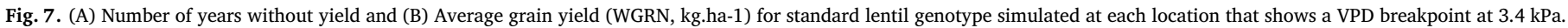

No genotypic differences in TR pattern were observed (data not shown). Average TR as a function of time $(\mathrm{t})$, when all data were combined, was best fitted with a polynomial equation: $T R=-3.9 t^{2}+42.4 t$ $+73.8\left(R^{2}=0.99\right)$, where ' $t$ ' is time (Fig. 3).

\subsection{TR response to variation of VPD in controlled environment}

The experiment in the growth chambers allowed direct regulation of VPD so the plants could be exposed to a larger range of VPD $(2.5 \mathrm{kPa}$ to $6.5 \mathrm{kPa}$ ). Over the 17 genotypes, 16 genotypes showed breakpoints and were fitted with a two-segment regression (Table 3). Most of the segmented regressions fitted the data well, with $\mathrm{R}^{2}$ ranging from 0.71 to 0.87 . In fact, the TR response to VPD was similar among genotypes (p-value $=0.19$ ). Also estimation of the slope at low VPD did not show significant differences among genotypes (average slope equal to $117 \mathrm{~g}$ $\mathrm{H}_{2} \mathrm{O} \mathrm{m}^{-2} \mathrm{~s}^{-1} \mathrm{kPa}^{-1}, \mathrm{SD}=26.8$ ). A similar consistency in results were in the breakpoints with values ranging from $3.33 \pm 0.25 \mathrm{kPa}$ to $3.87 \pm 0.41 \mathrm{kPa}$ and an average of $3.4 \mathrm{kPa}(\mathrm{SD}=0.16)$. The slope at VPD greater than the breakpoint ranged from $13.5 \pm 11.58$ to $30.0 \pm 9.944\left(\mathrm{~g} \mathrm{H}_{2} \mathrm{O} \mathrm{m}^{-2} \mathrm{~s}^{-1} \mathrm{kPa}^{-1}\right)$ and an average of $23.8 \mathrm{~g} \mathrm{H}_{2} \mathrm{O}$ $\mathrm{m}^{-2} \mathrm{~s}^{-1} \mathrm{kPa}^{-1}$ (S.D. $=2.1$ ). The exceptional genotype was DPL 53, which did not show a significant breakpoint ( $\mathrm{p}$-value $=0.1$ ) and was fitted using a linear regression model to increasing VPD (Fig. 4) $\left(R^{2}=0.6\right)$.

\subsection{Model predictions}

\subsubsection{Rainfall spatial distribution}

The calculated cumulative rainfall (Fig. 5A) during the simulated crop cycle (that ranged between 70 to 90 days depending on the regions) reflected the fact that large areas of South Asia are drylands (0-100 mm during the crop cycle). As expected, the driest part corresponded to the Thar Desert in the south of Pakistan, but the central part of India also has a scarcity of rainfall with a high aridity index. Cumulative precipitation was less than $60 \mathrm{~mm}$ over the following Indian states: Rajasthan, Madhya Pradesh and Gujarat. In contrast, the south of India, north of Afghanistan and Pakistan, and all the east coast of India received larger amounts of rainfall (between 100-400 mm) during the simulated crop cycle.

The calculated maximum midday VPD during the simulated crop cycle followed more or less the same pattern as cumulative rainfall (Fig. 5B). Deserts in South of Pakistan and central parts of India, had maximum midday VPD values above $2.5 \mathrm{kPa}$, reaching a maximum of 4.7 in the most arid areas (Fig. 5B).

\subsubsection{Baseline simulation}

The simulated sowing dates (Fig. 5) that were found by the model ranged between 10 September to 25 December across locations. Therefore, in the Southern regions of India, sowing date was in December, while in the northeast and in the central regions of India, the model sowed in early October except in Arunachal Pradesh where the sowing occurred in November. Sowing was earlier in the Western part of India (20 September to 5 October) and even earlier in Afghanistan and Pakistan (10-20 September).

The Baseline scenario that was parameterized for a VPD response with a breakpoint at $3.4 \mathrm{kPa}$. Fig. 6 results a map showing potential production of lentil with this trait over India, Afghanistan, Pakistan, and Nepal. Not surprisingly, the number of years without yield over 30 years of simulation varied considerably across locations (Fig. 6). The regions of mountains of the Northwest, in Thar Desert and in south India had the largest number of years without yield (over 20 out of 30 years). The rest of the regions had a range of 4 and 20 years without yield. This high number of years without yield was due to plant mortality at different stages during the crop cycle. In $73 \%$ of the cases, the crop did not germinate. Another cause of mortality (21\% of the cases) was the low leaf area development due to early senescence during the vegetative phase. Impossibility to sow because of dry conditions during the sowing window occurred only in $4 \%$ of the cases.

Average yield across all years for each location (Fig. 6) was to a large extent influenced by the number of years without yield. That is, production was low in the mountains of the Northwest, in Thar Desert and in south India $\left(0-400 \mathrm{~kg} \mathrm{ha}^{-1}\right)$. Much of the remaining locations had average yields ranging from 400 to $800 \mathrm{~kg} \mathrm{ha}^{-1}$. Only the northern part of India (Assam, Bihar, Uttar Pradesh), Bangladesh and parts of Nepal had higher yields $\left(800-1500 \mathrm{~kg} \mathrm{ha}^{-1}\right)$.

\subsubsection{Simulation results from limited-transpiration trait}

To examine the questions about where and by how much lentil yield is expected to be impacted as a result of the limited-transpiration trait under high VPD, three additional scenarios with differing VPD responses were simulated. The results are presented in maps showing the number of years without yield, the average change in yield in comparison to the baseline scenario, and the probability of yield increase (Fig. 7).

Results did not show major differences between the baseline simulation and the VPD insensitive-scenario (Fig. 7). The number of years without yield is exactly the same as in the baseline scenario. The absolute yield increase did not exceed $30 \mathrm{~kg} \mathrm{ha}^{-1}$ in Northern and Eastern India. The probability of yield increase is equal to zero for most 


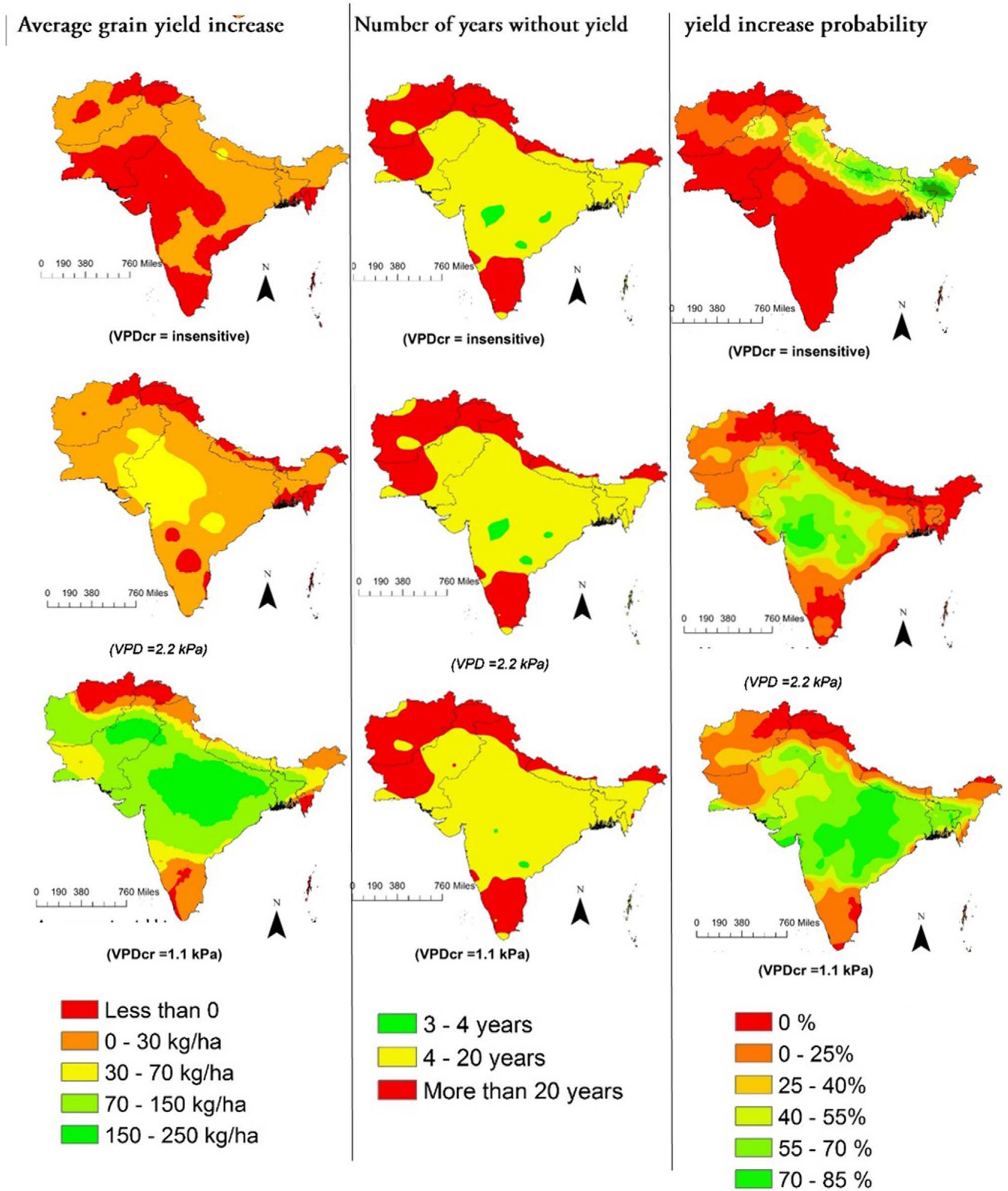

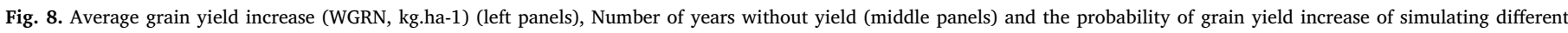

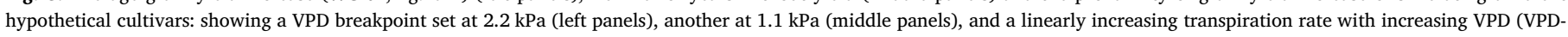
insensitive, right panels) as compared to a lentil genotype that shows a VPD breakpoint at $3.4 \mathrm{kPa}$.

part of South Asia except for parts in Northern India (Uttar Pradesh and Bihar), Nepal and Bangladesh that showed higher probability of yield increase. These areas correspond to the areas that showed the highest yield in the baseline scenario.

Compared to the baseline scenario, the scenario with a VPD breakpoint at $2.2 \mathrm{kPa}$ (Fig. 7) did not have a major impact on the number of years without yield but did increase grain yield in the central and western parts of India (parts of Uttar Pradesh, Madhya Pradesh, Rajasthan and Gujarat). The average increase in yield varied between $30 \mathrm{~kg} \mathrm{ha}^{-1}$ and $70 \mathrm{~kg} \mathrm{ha}^{-1}$ which represent approximatively an $8 \%$ increase in average yield over the baseline scenario. Probability of yield increase was above $50 \%$ in the same regions where the average yield increase was the highest.

The last scenario with a VPD breakpoint at $1.1 \mathrm{kPa}$ gave the greatest 
yield improvement, compared to the baseline scenario (Fig. 7). The number of years without yield remained unchanged, compared to the baseline scenario but the yield increased greatly in most parts of India, and large areas of Bangladesh and Nepal and some parts of Pakistan and Afghanistan. Average grain yield increase was between 70 and $150 \mathrm{kgha}^{-1}$ in most places and over $150 \mathrm{~kg} \mathrm{ha}^{-1}$ in the central part of India (Fig. 7) which is equivalent to $15-30 \%$ increase of yield. The probability of yield increase was around 55\% all over India except for the extreme southern regions (Karnataka, Andhra Pradesh, Tamil Nadu and Kerala) and the Arunachal Pradesh region. This probability was the lowest (around 25\%) in Afghanistan and Pakistan (Fig. 7).

\section{Discussion}

\subsection{Lentil genotypes transpiration response to high VPD}

This is the first time that lentil genotypic variation is investigated for TR response to VPD. Seventeen lentil genotypes were studied in an outdoor experiment and none showed a clear breakpoint in their TR response to VPD (VPD below $3 \mathrm{kPa}$ ) (Fig. 1). The limited data taken under high VPD in the outdoor experiment appears to have not allowed detection of a breakpoint in the response to VPD. Transpiration rate may have been regulated outdoors to a small extent since TR decreased around 13:00 when VPD was at its maximum.

To expand the range of VPD to which the plants were subjected, experiments in a controlled environment were undertaken. In the range of 2-6 kPa, almost all lentil genotypes (Fig. 2), except one (DPL 53; Fig. 4) exhibited a breakpoint at about $3.4 \mathrm{kPa}$ (Table 2). As in the outdoors experiment, no significant genotypic differences were found in the estimated parameters (BP and slopes) (Table 2) except for the genotype that did not show a breakpoint in response to VPD increase. These results indicated that lentil appears to have the genetic capacity to regulate their transpiration to VPD but that the limited-transpiration trait exists in lentil at greater VPD values $(\sim 3.4 \mathrm{kPa})$ than those commonly reported in other crop species. Previous studies reporting transpiration sensitivity to VPD such as in soybean (Gilbert et al., 2011; Sadok and Sinclair, 2009a,b), peanut (Devi et al., 2010), sorghum (Gholipoor et al., 2010), chickpea (Zaman-Allah et al., 2011), pearl millet (Kholová et al., 2010), maize (Yang et al., 2012; Gholipoor et al., 2013), and wheat (Schoppach and Sadok, 2012), have mostly registered values of BP ranging from 1.1 to $2.7 \mathrm{kPa}$. Only wheat have shown high breakpoint (3.9 kPa) (Schoppach and Sadok, 2012).

Since these experiments were performed in growth chambers, it is likely that the high temperatures $\left(>35^{\circ} \mathrm{C}\right.$ ) that were required to reach higher VPD values played a role in the observed responses. It is difficult to clarify interactions between plant VPD responses and temperature from existing literature because these interactions are often confounded experimentally (Sermons et al., 2012; Shekoofa et al., 2016). However, recently, Shekoofa et al. (2016) investigated the conservation of the BP in maize lines expressing the limited transpiration trait at $32{ }^{\circ} \mathrm{C}$ under temperatures up to $38^{\circ} \mathrm{C}$. Interestingly, this study reported that some maize hybrids had lost the VPD breakpoints when temperature increased from 36 to $38{ }^{\circ} \mathrm{C}$. These results clearly demonstrated the importance of temperature in VPD response and open the way to genotypic selection depending on the environment and temperature where the crop is grown.

The simulation study showed that breakpoint found in these lentil lines occurred at such a high VPD $(3.4 \mathrm{kPa})$ that it would not be very useful in terms of impacting water conservation under field conditions. Despite the high observed values of BP in response to VPD variation, this preliminary genetic screening showed that the limited-transpiration trait at elevated VPD does exist in lentil and, therefore, supports the investigation by simulation of the impact on yield of various BP values.

\subsection{Lowering the BP can result in an increase in average yield and probability of yield increase in the dry areas of south asia}

Considering the breadth of geographical area and environments in which lentil is grown in South Asia (Erskine et al., 2009), an assessment of having a lower BP in lentil can only be done by using simulations done over the range of locations and weather conditions. Large scale assessment of this trait using a mechanistic model has been previously reported for soybean production in the USA (Sinclair et al., 2010), Africa (Sinclair et al., 2014) and groundnut in sub-Saharan Africa (Vadez et al., 2017).

Simulation results showed that the sowing dates chosen by the model follow the progression of the monsoon (Fig. 5); coinciding with the sowing windows reported for lentil in the literature (see Erskine et al., 2009 for a review). In the northern parts of India, where lentil is grown, simulation results indicated sowing time in October. In the same areas it is recommended to sow before the 25 November (Gupta and Parihar, 2015). In the central zone of India, where moisture is limiting, it is recommended to sow before mid-October which corresponds to the simulated sowing dates (Fig. 5). In the Southern India (mainly Tamil Nadu, where lentil is not grown) sowing date have been simulated in December. The inability to obtain yield in two or more growing seasons out of 30 was previously used as a criterion to identify the geographical areas in South Asia for consistent low-risk, lentil production (Sinclair et al., 2014; Ghanem et al., 2015a,b). Simulation results show a high risk lentil production (between 4-20 years) in most of the simulated regions (Fig. 6). It is possible that in some of these areas, the risk of crop failure was over estimated by the model due to poor germination related to erroneous sowing dates. But given that simulations results of sowing dates are satisfactory, the high number of years without yield might be due to other factors such as temperature or drought that have caused the crop not to germinate or accelerated leaf senescence during the vegetative stage. Indeed, the simulation results of the cumulative rainfall during the crop cycle show that lentil is mainly grown on residual moisture in relatively arid regions that receive only 30-100 mm of precipitation during the crop cycle (Fig. 5).

The simulation results presented here using the baseline parameters, and phenology already published for lentil (Ghanem et al., 2015a), as well as a VPD breakpoint at $3.4 \mathrm{kPa}$ (chosen based on the experimental results reported here), showed that the model was able to predict regions of higher yield potential in South Asia that correspond to actual production areas. The simulations using the baseline parameters (BP at $3.4 \mathrm{kPa}$ ) predicted the highest yield potential for lentil in Nepal, Bangladesh, and Myanmar (Fig. 7). In India, higher yielding zones coincide with the states of Uttar Pradesh, Bihar, Madhya Pradesh, West Bengal and Assam. The simulation results in this study predicted a higher maximum average grain yield for the same areas with yield ranging between 1.2 and $1.5 \mathrm{tha}^{-1}$ (Fig. 7). Previous experimental studies reported an average yield for lentil in South Asia between 0.6-0.9 $\mathrm{k} \mathrm{tha}^{-1}$ (Yadav et al., 2007; Erskine, 2009; Singh and Singh, 2014). Yields of about $1.5 \mathrm{tha}^{-1}$ have been reported from experiments performed under irrigated conditions in India (Singh and Singh, 2014).

Lentil is mainly produced by smallholder farmers and most of the farmers follow a traditional farming system based on indigenous knowledge (Ghanem et al., 2015a,b). Since in one location nearly all management practices or traits can result, either in an increase or a decrease in yield depending on the weather of that individual growing season, it is important for crop breeders and farmers to understand the probability of yield increase (Sinclair et al., 2014) before pursuing any change in trait. Results showed that the number of years without yield was not modified significantly by the different VPD breakpoint scenarios. However, simulated probability of yield gain as a result of imposing a VPD breakpoints at 2.2 or $1.1 \mathrm{kPa}$ was very high (Fig. 8).

Virtually all major lentil production areas of central and north India, as well as Nepal and Bangladesh had a probability of yield gain greater than $70 \%$. The highest probability of yield gain was reached for the 
scenario with a VPD breakpoint at $1.1 \mathrm{kPa}$ (Fig. 8 ven though the trait restricted stomatal conductance under high VPD conditions causing an immediate in carbon assimilation rate, no yield loss over the entire season was simulated in nearly all locations where lentil is currently produced. Yield increase was observed in the same areas where the probability of yield gain was the highest (Fig. 8). These areas coincided also with water-limited environments (Fig. 5) since most of the simulated yield gains occurred in the driest areas.

One of the key findings of this study is that there is a potential to further increase lentil yield in many areas of South Asia by targeting limited-transpiration rate at high VPD. Obviously, more experimental screenings are needed to evaluate genetic material of lentil in order to find genotypes that show a VPD breakpoint less than $2 \mathrm{kPa}$.

In most locations, simulation results show that lentil genotypes that had VPD breakpoints at 2.2 or $1.1 \mathrm{kPa}$ had a longer crop cycle compared to the baseline scenario (data not shown). The water saving trait during the crop cycle may have decreased the probability of having drought towards the end of the growing season. Indeed, the only places where there was not a high probability of yield increase as a result of the limited-transpiration trait were either areas where lentil is currently not produced (because of other reasons), like Southern India or northern areas of Pakistan and Afghanistan (Fig. 7 or areas that received the highest precipitation (Fig. 4) during the crop cycle maybe because in these areas, lentil did not suffer from drought stress and the presence of a breakpoint did not increase the crop cycle.

\section{Conclusion}

Outcomes from this study provide evidence for a plausible role of the limited transpiration trait under high VPD in future genetic improvement efforts for lentil. There is a need for additional experiments in search for lentil germplasm with a low breakpoint.

\section{Acknowledgments}

This work was supported by the CGIAR Research Program on Grain Legumes and the USAID/CGIAR-US Universities Linkage Program.

\section{Appendix A. Supplementary data}

Supplementary data associated with this article can be found, in the online version, at http://dx.doi.org/10.1016/j.fcr.2017.04.013.

\section{References}

Belko, N., Zaman-Allah, M., Diop, N.N., Cisse, N., Zombre, G., Ehlers, J.D., Vadez, V., 2013. Restriction of transpiration rate under high vapor pressure deficit and nonlimiting water conditions is important for terminal drought tolerance in cowpea. Plant Biol. 15, 304-316.

Chakraborty, U., Pradhan, D., 2011. High temperature-induced oxidative stress in Lens culinaris, role of antioxidants and amelioration of stress by chemical pretreatments. J. Plant Interact. 6 (1), 43-52.

Chen, W., Sharma, H.C., Muehlbauer, F.J., 2011. Crop Protection Compendium for Chickpea and Lentil Diseases and Pests. The American Phytopathological Society, St Paul, Minnesota, USA (166 pp).

Datta, S., Tiwari, S., Kaashyap, M., Gupta, P.P., Choudhury, P.R., Kumari, J., Kumar, S., 2011. Genetic similarity analysis in Lentil using cross-genera legume sequence tagged Microsatellite site markers. Crop Sci. 51, 2412-2422. http://dx.doi.org/10.2135/ cropsci2010.12.0743.

Davies, R.B., 1987. Hypothesis testing when a nuisance parameter is present only under the alternative. Biometrika 74, 33-43.

Dee, D.P., Uppala, S.M., Simmons, J., Berrisford, P., Poli, P., Kobayashi, S., Andrae, U., Balmaseda, M., Balsamo, G., Bauer, P., Bechtold, P., Beljaars, C.M., van de Berg, L., Bidlot, J., Bormann, N., Delsol, C., Dragani, R., Fuentes, M., Geer, J., Haimberger, L., Healy, S.B., Hersbach, H., Holm, E.V., Isaksen, L., Kallberg, P., Kohler, M., Matricardi, M., McNally, P., Monge-Sanz, B.M., Morcrette, J.J., Park, B.K., Peubey, C., de Rosnay, P., Tavolato, C., Thepaut, J.N., Vitart, F., 2011. The ERA-Interim reanalysis: configuration and performance of the data assimilation system. Q. J. R. Meteorol Soc. 137, 553-597.

Devi, J.M., Sinclair, T.R., Vadez, V., 2010. Genotypic variation in peanut for transpiration response to vapor pressure deficit. Crop Sci. 50, 191-196.

Devi, J.M., Taliercio, E.W., Sinclair, T.R., 2015. Leaf expansion of soybean subjected to high and low atmospheric vapour pressure deficits. J. Exp. Bot. 66, 1845-1850.

Donat, M.G., Lowry, A.L., Alexander, L.V., O'Gorman, P.A., Maher, N., 2016. More extreme precipitation in the world's dry and wet regions. Nat. Clim. Change 6, 508-513.

Erskine, W., Muehlbauer, F.J., Sarker, A., Sharma, B., 2009. The Lentil: Botany, Production and Uses. CAB International (447p).

Fasullo, J., Webster, P.J., 2003. A hydrological definition of indian monsoon onset and withdrawal. J. Clim. 16, 3200-3211.

Fletcher, A.L., Sinclair, T.R., Allen Jr, L.H., 2007. Transpiration responses to vapor pressure deficit in well-watered slow wilting and commercial soybean. Environ. Exp. Bot. 61, 145-151.

Ghanem, M.E., Marrou, H., Soltani, A., Kumar, S., Sinclair, T.R., 2015a. Lentil variation in phenology and yield evaluated with a model. Agron. J. 107, 1967-1977.

Ghanem, M.E., Marrou, H., Biradar, C., Sinclair, T.R., 2015b. Production potential of lentil (Lens culinaris medik.) in east africa. Agric. Syst. 137, 24-38.

Gholipoor, M., Vara, Prasad P.V., Mutava, R.N., Sinclair, T.R., 2010. Genetic variability of transpiration response to vapor pressure deficit among sorghum genotypes. Field Crops Res. 119, 85-90.

Gholipoor, M., Choudhary, S., Sinclair, T.R., Messina, C.D., Cooper, M., 2013. Transpiration response of maize hybrids to atmospheric vapour pressure deficit. J. Agro Crop Sci. 199, 155-160 (ISSN 0931-2250. Blackwell Verlag GmbH).

Gilbert, M.E., Zwieniecki, M.A., Holbrook, N.M., 2011. Independent variation in photosynthetic capacity and stomatal conductance leads to differences in intrinsic water use efficiency in 11 soybean genotypes before and during mild drought. J. Exp. Bot. 62, 2875-2887.

Goudriaan, J., van Laar, H.H., 1994. Modelling Potential Crop Growth Processes. Kluwer Academic Press, Dordrcht, The Netherlands (238).

Gupta, S., Parihar, A.K., 2015. Lentil Cultivation in India: Pocket Guide AICRP on MULLaRP. Indian Institute of Pulses Research, Kanpur, India (35 p).

Janzen, J.P., Brester, G.W., Smith, V.H., 2014. Lentils: Trends in Production, Trade, and Price. Agricultural Marketing (briefing n61).

Kholová, J., Hash, C.T., Kumar, P.L., Yadav, R.S., Kocova, M., Vadez, V., 2010. Terminal drought-tolerant pearl millet [Pennisetum glaucum (L) R: Br.] have high leaf ABA and limit transpiration at high vapour pressure deficit. J. Exp. Bot. 61, 1431-1440.

Kholová, J., Tharanya, M., Kaliamoorthy, S., Malayee, S., Baddam, R., Hammer, G.L. McLean, G., Deshpande, S., Hash, C.T., Craufurd, P.Q., Vadez, V., 2014. Modelling the effect of plant water use traits on yield and stay-green expression in sorghum. Funct. Plant Biol. 41 (10-11), 1019-1034.

Kumar, J., Basu, P.S., Srivastava, E., Chaturvedi, S.K., Nadarajan, N., Kumar, S., 2012 Phenotyping of traits imparting drought tolerance in lentil. Crop Pasture Sci. 63, 547-554.

Kumar, J., Srivastva, E., Singh, M., 2013. Genetics of early growth vigour in lentil (Lens culinaris Medik.). J. Genet. 92, 323-326.

Kumar, J., Kant, R., Kumar, S., Basu, P.S., Sarker, A., Singh, N.P., 2016. Heat tolerance in lentil under field conditions. Legume Genomics Genet. 7 (1), 1-11.

Materne, M., Siddique, K., 2009. Agro-ecology and Crop Adaptation in The Lentil Botany, Production and Uses. CABI International, UK, pp. 47-63.

Messina, C.D., Sinclair, T.R., Hammer, G.L., Curan, D., Thompson, J., Oler, Z., Gho, C., Cooper, M., 2015. Limited-transpiration trait may increase maize drought tolerance in the US Corn Belt. Agron. J. 107, 1978-1986.

Mishra, B.K., Singh, A.K., Lal, J.P., Srivastava, J.P., 2016. Drought stress resistance in lentil. In: National Symposium on Vegetable Legumes for Soil and Human Health. Varanasi, February 2016.

Rebetzke, G.J., Condon, A.G., Richards, R.A., Farquhar, G.D., 2003. Genetic control of leaf conductance in three wheat crosses. Aust. J. Agric. Res. 54, 381-387.

Riar, M.K., Sinclair, T.R., Vara Prasad, P.V., 2015. Persistence of limited-transpirationrate trait in sorghum at high temperature. Environ. Exp. Bot. 115, 58-62.

Richards, R.A., Passioura, J.B., 1989. A breeding program to reduce the diameter of the major xylem vessel in the seminal roots of wheat and its effect on grain yield in rainfed environments. Aust. J. Agric. Res. 40, 943-950.

Sadok, W., Sinclair, T.R., 2009a. Genetic variability of transpiration response to vapor pressure deficit among soybean (Glycine max [L] Merr.) cultivars. Crop Sci. 49, 955-960.

Sadok, W., Sinclair, T.R., 2009b. Genetic variability of transpiration response to vapor pressure deficit among soybean (Glycine max [L] Merr.) genotypes selected from a recombinant inbred line population. Field Crops Res. 113, 156-160.

Schoppach, R., Sadok, W., 2012. Differential sensitivities of transpiration to evaporative demand and soil water deficit among wheat elite cultivars indicate different strategies for drought tolerance. Environ. Exp. Bot. 84, 1-10.

Sermons, S.M., Seversike, T.M., Sinclair, T.R., Fiscus, E., Rufty, T., 2012. Temperature influences the ability of tall fescue to control transpiration in response to atmospheric vapour pressure deficit. Funct. Plant Biol. 39, 979-986.

Seversike, T.M., Sermons, S.M., Sinclair, T.R., Carter, TE Jr., Rufty, T.W., 2013. Temperature interactions with transpiration response to vapor pressure deficit among cultivated and wild soybean genotypes. Physiol. Plant. 148, 62-73.

Shekoofa, A., Devi, J.M., Sinclair, T.R., Holbrook, C.C., Isleib, T.G., 2013. Divergence in drought-resistance traits among parents of recombinant 1 peanut inbred lines. Crop Sci. 53, 2569-2576.

Shekoofa, A., Balota, M., Sinclair, T.R., 2014. Limited-transpiration trait evaluated in growth chamber and field for sorghum genotypes. Environ. Exp. Bot. 99, 175-179.

Shekoofa, A., Sinclair, T.R., Messina, C.D., Cooper, M., 2016. Variation among Maize hybrids in response to high vapor pressure deficit at high temperatures. Crop Sci. $55,1-5$.

Sinclair, T.R., Hammer, G.L., van Oosterom, E.J., 2005. Potential yield and water-use efficiency benefits in sorghum from limited maximum transpiration rate. Funct. Plant Biol. 32, 945-952. 
Sinclair, T.R., Zwieniecki, M.A., Holbrook, N.M., 2008. Low leaf hydraulic conductance associated with drought tolerance in soybean. Physiol. Plant. 132, 446-451.

Sinclair, T.R., Messina, C.D., Beatty, A., Samples, M., 2010. Assessment across the United States of the benefits of altered soybean drought traits. Agron. J. 102, 475-482.

Sinclair, T.R., Marrou, H., Soltani, A., Vadez, V., Chandolu, K.C., 2014. Soybean production potential in Africa. Global Food Sec. 3, 31-40.

Sinclair, T.R., Devi, J.M., Carter, T.E., 2016. Limited-transpiration trait for increased yield for water-limited soybean: from model to phenotype to genotype to cultivars. In: Yin, X., Struik, P.C. (Eds.), Crop Systems Biology -narrowing the Gaps Between Crop Modelling and Genetics. Springer, Zurich, pp. 129-146.

Singh, K.M., Singh, R.K.P., 2014. Lentil in India: An Overview (October 16, 2014). (Available at SSRN: https://ssrn.com/abstract $=2510906$ or http://dx.doi.org $/ 10$ 2139/ssrn.2510906).

Soltani, A., Sinclair, T.R., 2012. Modeling Physiology of Crop Development, Growth and Yield. CABI, Wallingford, Oxfordshire, UK.

Tanner, C.B., Sinclair, T.R., 1983. Efficient water use in crop production: research or research? In: Taylor, H.M., Jordan, W.R. (Eds.), Limitations to Efficient Water Use in Crop Production. ASA, CSSA, and SSSA, Madison, WI, pp. 1-27.

Tukey, J., 1977. Exploratory Data Analysis. Addison-Wesley, Reading, MA.

Uppala, S., Kallberg, P., Simmons, A., Andrae, U., daCosta Bechtold, V., Fiorino, M.,

Gibson, J., Haseler, J., Hernandez, A., Kelly, G., Li OK, X., Saarinen, S., Sokka, N.,
Allan, R., Andersson, E., Arpe, K., Ma, B., Beljaars, A., van de Berg, L., Bidlot, J., Bormann, N., Caires, S., Chevallier, F., Dethof, A., Dragosavac, M., Fisher, M., Fuentes, M., Hagemann, S., Hlm, E., Hoskins, B., Isaksen, L., Janssen, P., Jenne, M.A.R., Mahfouf, J.F., Morcrette, J.J., Rayner, N., Saunders, R., Simon, P., Sterl, A., Trenberth, K., Untch, A., Vasiljevic, D., Viterbo, P., Woollen, J., 2005. The ERA-40 reanalysis. Q. J. R. Meteorol. Soc. 131, 2961-3012.

Vadez, V., Kholova, J., Medina, S., Aparna, K., Anderberg, H., 2014. Transpiration efficiency: new insights into an old story. J. Exp. Bot. 65, 6141-6153.

Vadez, V., Halilou, O., Hissene, H.M., Sibiry-Traore, P., Sinclair, T.R., Soltani, A., 2017. Mapping water stress incidence and intensity, optimal plant populations, and cultivar duration for african groundnut productivity enhancement. Front. Plant Sci. 8, 432. http://dx.doi.org/10.3389/fpls.2017.00432.

Yadav, S.S., McNeil, D.L., Stevenson, P.C., 2007. Lentil: An Ancient Crop for Modern Times. Springer Science \& Business Media (486 pages).

Yang, Z., Sinclair, T.R., Messina, C.D., Cooper, M., Hammer, G.L., 2012. Temperature effect on transpiration response of maize plants to vapour pressure deficit. Environ. Exp. Bot. 78, 157-162.

Zaman-Allah, M., Jenkinson, D.M., Vadez, V., 2011. Chickpea genotypes contrasting for seed yield under terminal drought stress in the field differ for traits related to control of water use. Funct. Plant Biol. 38, 270-328. 